\title{
A REFORMA DA EDUCAÇÃO SUPERIOR DO GOVERNO LULA: AUTONOMIA RELATIVA E FINANCIAMENTO*
}

\author{
Nelson Cardoso Amaral ${ }^{* *}$
}

\section{RESUMO}

Este estudo discute os rumos da reforma da educação superior desencadeada pelo governo Lula sob a ótica da autonomia e do financiamento, além de apresentar as propostas para a educação superior presentes no programa de governo Uma Escola do Tamanho do Brasil discutidas durante a campanha eleitoral de 2001. São apresentadas alertas e preocupações em relação a diversos pontos presentes nas duas versões já divulgadas e conclui que parece existir um processo histórico que não quer implementar uma verdadeira autonomia para as universidades federais brasileiras, já que as normatizações tratam de relativizá-la, deixando obscuras as condições para o financiamento.

Palavras-chave: autonomia; financiamento; educação superior.

\section{INTRODUÇÃO}

A origem das instituições federais de ensino superior (Ifes) e, em consequiência, as discussões sobre o financiamento das suas atividades estão na Universidade do Rio de Janeiro, criada em 1920, transformada na Universidade do Brasil, em 5 de julho de 1937, e na Universidade Federal do Rio de Janeiro (UFRJ), a partir de 1965. A Universidade do Brasil era "entendida como o grande projeto universitário do Governo, a partir de 1931, e implantada, em 1937, como modelo para as demais instituições de ensino superior do País" (FÁvero, 2000a, p. 12).

\footnotetext{
* Artigo recebido em 15/06/2005 e aprovado em 30/06/2005.

** Doutor em Educação pela Unimep, professor do Instituto de Física e do Programa de PósGraduação em Educação da Faculdade de Educação da UFG. [e-mail: nelson1@if.ufg.br]
} 
A fundamentação do projeto está presente na reforma do ensino superior promovida pelo ministro Francisco Campos, cujo conteúdo foi publicado no Diário Oficial de 15 de abril de 1931, e que continha o Estatuto das Universidades Brasileiras (FÁvERo, 2000b). Na chamada Reforma Francisco Campos, foi adotada como regra a organização do ensino superior em universidades, abandonando-se o modelo colonial de faculdades isoladas; a universidade não seria mais o local onde só se ensinava, mas passaria a ser um local em que a pesquisa pura desinteressada e a ampliação do saber teriam lugar assegurado; a instituição universitária deveria interagir com a sociedade, desenvolvendo projetos de extensão, atuando sobre e com a sociedade, com o objetivo de analisar, discutir e resolver os problemas que a afligem. $\mathrm{O}$ documento tratava ainda do estabelecimento da autonomia para a universidade.

Com o argumento de que a universidade no Brasil era recente e ainda não havia acumulado experiência que permitisse ao Estado implementar uma autonomia integral, o projeto falava em autonomia relativa; a autonomia plena seria "obra de conquista de espírito universitário, amadurecimento experiente e dotado do seguro e firme sentido de direção e de responsabilidade":

Este o motivo pelo qual o projeto preferiu a orientação prudente e segura da autonomia relativa, destinada a exercer uma grande função educativa sobre o espírito universitário, que na sua prática adquirirá a experiência e o critério indispensáveis a uma autonomia mais ampla, seja no terreno administrativo, seja no domínio didático. Com a experiência poderá o quadro da autonomia ir se alargando de maneira gradual e progressiva até que, finalmente, com o desenvolvimento da capacidade e da envergadura do espírito universitário, este venha a reunir sob a sua autoridade todos os poderes de governo do grande agrupamento administrativo, técnico e didático que constitui a universidade. A autonomia integral será, assim, obra de conquista de espírito universitário, amadurecido, experiente e dotado do seguro e firme sentido de direção e de responsabilidade, ao invés de constituir uma concessão graciosa e extemporânea, destinada antes a deseducar do que a formar, no centro universitário, o senso de organização, de comando e de governo. (FÁvero, 2000b, p. 23-24; grifos nossos)

A idéia de autonomia relativa materializou-se quando ficou definido que ela se restringiria à autonomia administrativa, didática e 
disciplinar, nos limites estabelecidos pelo estatuto, não se referindo a nenhum grau de autonomia de gestão financeira.

Como reação a essa proposta, o Conselho da Universidade do Rio de Janeiro, por unanimidade, em 4 de março de 1934, se pronunciaria contundentemente sobre a autonomia relativa, sem a consequiente definição de uma autonomia de gestão financeira:

Torna-se ilusória a autonomia didática não acompanhada da administrativa, e esta última não pode, praticamente, existir sem a autonomia financeira.

Pode-se, mesmo, dizer que o grau de autonomia didática e administrativa de instituições de educação e ensino se mede pela amplitude da autonomia financeira que lhes é proporcionada. (FÁvero, 2000a, p. 143; grifos nossos)

Apesar de todos os protestos, a Universidade do Brasil foi implantada pela Lei n. 452, de 5 de julho de 1937, sem qualquer definição sobre sua autonomia; esse tema somente viria a ser tratado em 1945, com a edição do Decreto-Lei n. 8.393, de dezembro, que em seu artigo 1 estabeleceu: "A Universidade do Brasil, instituição de ensino superior cujos fins estão fixados na Lei n. 452, de 5 de junho de 1937, passará a ser pessoa jurídica, com autonomia administrativa, financeira, didática e disciplinar, nos termos do presente Decreto-Lei" (FÁvERO, 2000b, p. 181; grifos nossos).

Os recursos para manutenção e desenvolvimento dos serviços da universidade - conservação, renovação e ampliação de suas instalações - seriam provenientes de:

a) dotações orçamentárias que lhe forem atribuídas pela União, na forma do artigo 23;

b) dotações, a título de subvenção, que lhe atribuírem os Estados, o Distrito Federal e os Municípios;

c) doações que a esse título receber de pessoas físicas ou jurídicas;

d) renda de aplicação de bens patrimoniais;

e) retribuição das atividades remuneradas dos laboratórios e quaisquer outros serviços;

f) taxas e emolumentos escolares;

g) receita eventual. 
O artigo 23 definia como deve ser a dotação orçamentária da Universidade do Brasil:

A lei que fixar anualmente a despesa da União consignará a subvenção necessária ao pagamento de todo o pessoal permanente e extranumerário da Universidade e ainda o de material indispensável aos serviços dos estabelecimentos de ensino e dos institutos técnicocientíficos que a constituírem.

$\S 1^{\circ}$ A dotação referente aos servidores públicos lotados na Universidade do Brasil será distribuída à Tesouraria do Ministério da Educação e Saúde, que efetuará o pagamento, segundo as folhas de exercício expedidas pela Reitoria.

$\S 2^{\circ}$ A dotação destinada a material será depositada no início de cada exercício financeiro no Banco do Brasil, à disposição do Reitor da Universidade.

$\S 3^{\circ}$ O Departamento de Administração do Ministério da Educação e Saúde providenciará para que, encerrado o exercício financeiro, qualquer saldo existente à conta de pessoal seja incorporado à conta de bens patrimoniais da Universidade, por intermédio do Banco do Brasil.

Em 1962, no dia 24 de fevereiro, o Conselho Universitário da Universidade do Brasil constituiu uma comissão encarregada de realizar um estudo que provocasse mudanças na instituição. Ao tratar de sua conceituação, afirma-se que a autonomia é condição básica da Universidade, e a autonomia de gestão financeira seria decorrente de:

- propriedade de patrimônio rentável e passível de mobilização;

- renda própria, originária de taxas ou de serviços remunerados prestados a pessoas físicas e jurídicas, de direito público e privado;

- dotações, consignadas em orçamentos oficiais, correspondentes à retribuição de serviços prestados à comunidade;

- doações e colaborações financeiras provenientes de convênios de que resultam obrigações específicas;

- gestão financeira própria, segundo normas adequadas ao seu funcionamento. (Grifos nossos). 
Está presente a preocupação com a definição de um patrimônio que seja rentável, como forma de propiciar a autonomia de gestão financeira. Fala-se, também, na prestação de serviços remunerados como uma das fontes de recursos da universidade.

Houve, portanto, na origem das Ifes, uma indefinição sobre as regras de seu financiamento. Não houve a vinculação de patrimônio, nem a constituição de fundos que garantissem a continuidade de recursos financeiros para a manutenção e o desenvolvimento das instituições. A obrigatoriedade do financiamento público ficou estabelecida no artigo 23 , sem, entretanto, definir-se concretamente como seria o cumprimento dessa norma legal.

A situação hoje não é muito diferente; as instituições, salvo exceções, como a Universidade de Brasília, não possuem patrimônio e fundos que gerem recursos financeiros. A Lei n. 9.394/96, a LDB, também estabeleceu em seu artigo 55 que "Caberá à União assegurar, anualmente, em seu Orçamento Geral, recursos suficientes para manutenção e desenvolvimento das instituições de educação superior por ela mantidas"; formulação legal muito parecida com a do artigo 23 do Decreto n. 8.393, de 17 de dezembro de 1945, que delineou como deveria ser a autonomia da Universidade do Brasil, mas que também não define concretamente a forma de se estabelecer o montante de recursos que assegurem a manutenção e o desenvolvimento das instituições. Portanto, quando se trata de autonomia e financiamento, muito há por se definir.

As ações do governo Lula ainda não traduziram o que foi preconizado no programa Uma Escola do Tamanho do Brasil, apresentado durante a campanha eleitoral de 2001.

No período em que o MEC esteve sob o comando de Cristóvam Buarque a ação mais visível em relação ao ensino superior foi a instalação da Comissão Especial de Avaliação da Educação Superior (CEA) presidida pelo professor José Dias Sobrinho, da Unicamp, encarregada de "analisar, oferecer subsídios, fazer recomendações, propor critérios e estratégias para a reformulação dos processos e políticas de avaliação da Educação Superior e elaborar a revisão crítica de seus instrumentos, metodologias e critérios utilizados" (BRASIL. INEP, 2003).

Como resultado desse trabalho, após modificações importantes na proposta da CEA, o Congresso Nacional aprovou a Lei n. 10.861, de 14 de abril de 2004, que instituiu o Sistema Nacional de Avaliação da Educação Superior (Sinaes), com o objetivo de "assegurar processo 
nacional de avaliação das instituições de educação superior, dos cursos de graduação e do desempenho acadêmico de seus estudantes". Notase, portanto, que se optou por fracionar o processo avaliativo em três etapas, avaliar a instituição em sentido estrito, os cursos e os estudantes.

Além disso, o trabalho elaborado pela CEA evitou procedimentos que permitissem a elaboração de classificação entre as instituições e os cursos; entretanto, a lei dos Sinaes prevê para cada etapa de avaliação uma escala de cinco níveis, o que conduzirá, inevitavelmente, à elaboração de ranqueamentos.

O MEC, sob o comando de Tarso Genro, implementou o Programa Universidade para Todos (ProUni) que se destina à concessão de bolsas de estudo para cursos de graduação e seqüenciais de formação específica, em instituições privadas de ensino superior, com ou sem fins lucrativos, abriu uma ampla discussão sobre cotas étnicas e sociais nas instituições públicas e apresentou, em dezembro de 2004, uma proposta para a reforma da educação superior.

Após discussões das propostas presentes nesse documento de dezembro de 2004, intitulado "Estabelece normas gerais para a educação superior, regula o Sistema Federal da Educação Superior, e dá outras providências" (Primeira versão), o MEC divulgou em 30 de maio de 2005 uma segunda versão com o título: "Estabelece normas gerais para a educação superior, regula a educação superior no sistema federal de ensino e dá outras providências."

Neste estudo, iremos, primeiramente, apresentar pontos do programa de governo Uma Escola do Tamanho do Brasil, em seguida analisaremos sob a ótica da autonomia e do financiamento as duas versões apresentadas pelo governo Lula sobre a reforma da educação superior para, por fim, antes de concluir, apresentar alguns alertas e algumas preocupações.

A EDUCAÇÃo SUPERIOR NO PROGRAMa UMA Escola do TAMANHO DO BRASIL

O programa para a área da educação, apresentado pela candidatura de Luiz Inácio Lula da Silva, em sua introdução, discute a importância da educação na inserção do país no cenário internacional, quando afirma: 
A educação em todos os níveis é um direito social básico e universal. A educação é vital para romper com a histórica dependência científica, tecnológica e cultural e para a construção de uma nação autônoma, soberana e solidária consigo mesma e com outras nações.

O programa de governo valoriza, nesse aspecto, a educação superior e as instituições que desenvolvem ensino, pesquisa e extensão, além de preocupar-se com a demanda existente para esse nível de ensino:

A educação superior é reconhecida por seu valor na formação acadêmica e ética de recursos humanos, nas atividades de pesquisa científica e tecnológica e no desenvolvimento cultural, econômico e social. As fortes demandas populares por acesso à educação superior situam-na hoje no horizonte dos direitos sociais básicos. As universidades públicas e os institutos de pesquisa - na qualidade de instituições complexa, que detêm a síntese da capacidade intelectual, científica e cultural - devem ser valorizados e integrados ao processo de desenvolvimento nacional, considerando sua importância na recuperação da capacidade de produção própria de ciência e tecnologia e seu papel crítico diante da sociedade.

Para atuar concretamente nessas questões, o programa estabelece ações que se estruturam a partir do papel e das funções das instituições de educação superior. O programa afirma em sua apresentação que:

As concepções, diretrizes e metas a seguir apresentadas representam o acúmulo que o Partido dos Trabalhadores e os demais partidos da coligação têm nessa área, fruto da trajetória de lutas dos movimentos dos estudantes e trabalhadores da educação, das experiências vivenciadas por nossas administrações municipais e estaduais e da atuação das nossas bancadas parlamentares.

As propostas ali apresentadas estão, portanto, em consonância com idéias defendidas pelo partido que comanda o Poder Executivo. Registra-se, além disso, que os compromissos com a educação superior assumidos pelo governo Lula estão em sintonia com diversas ações previstas na $\mathrm{LDB}$ e no PNE, desde que sejam retomadas as propostas que foram vetadas pelo presidente Fernando Henrique Cardoso, quando da aprovação do PNE. 
Os compromissos básicos com a educação superior assumidos pelo governo Lula no programa Uma Escola do Tamanho do Brasil foram:

a) a promoção da autonomia universitária e da indissociabilidade entre ensino, pesquisa e extensão nos termos constitucionais (artigo 207 da CF);

b) o reconhecimento do papel estratégico das Universidades, em especial as do setor público, para o desenvolvimento econômico e social do país;

c) a consolidação das instituições públicas como referência para o conjunto das IES do país;

d) a expansão significativa da oferta de vagas no ensino superior, em especial no setor público e em cursos noturnos;

e) a ampliação do financiamento público ao setor público, revisão e ampliação do crédito educativo e criação do programa de bolsas universitárias, com recursos não vinculados à educação;

f) a defesa dos princípios constitucionais da gratuidade do ensino superior público (artigo 206, IV, da CF);

g) o envolvimento das IES, em especial as do setor público, com a qualificação profissional dos professores para a educação básica, em cursos que garantam formação de alta qualidade acadêmico-científica e pedagógica e associem ensino, pesquisa e extensão.

Uma das ações prioritárias do novo governo seria a criação de condições "para que através do esforço conjunto da União, Estados, Distrito Federal e municípios, o percentual de gastos públicos em educação em relação ao PIB sejam elevados para o mínimo de $7 \%$ no período de dez anos". Portanto, os novos recursos para as instituições de ensino superior estariam vinculados a essa elevação dos recursos para a educação pública brasileira.

Com vistas à ampliação da base de produção do conhecimento no país, as seguintes metas estão no programa:

a) ampliar, em quatro anos, as vagas no ensino superior, em taxas compatíveis com o estabelecido no PNE (Prover até o final da década, a oferta da educação superior para, pelo menos, $30 \%$ da faixa etária de 18 a 24 anos); 
b) ampliar a oferta de ensino público universitário, de modo a projetar, no médio prazo, uma proporção de no mínimo $40 \%$ do total de vagas, prevendo inclusive a parceria da União com os Estados na criação de novos estabelecimentos de educação superior (Meta referenciada em dispositivo do PNE aprovado pelo Congresso Nacional e vetado pelo presidente da República);

c) promover o aumento anual do número de mestres e de doutores formados no sistema nacional de pós-graduação em pelo menos 5\%, em conformidade com meta estabelecida pelo PNE;

d) planejar e incentivar, na graduação e pós-graduação, a oferta de cursos e vagas em áreas de conhecimento que melhor respondam às necessidades do projeto nacional de desenvolvimento.

A necessária ampliação da base de conhecimentos no país implica em um aumento significativo dos investimentos na área. Uma das fontes, como estabelece a meta 30 do PNE, é "utilizar parte dos recursos destinados à ciência e tecnologia, para consolidar o desenvolvimento da pós-graduação e da pesquisa", incluindo os fundos já existentes.

Uma outra proposta constante do programa é "Promover a autonomia universitária nos termos constitucionais, vinculando-a à democracia interna, baseada na tomada de decisões por órgãos colegiados representativos e no controle social mediante mecanismos abertos de prestação de contas e de avaliação institucional”. Tal proposição, corrobora com a meta cinco do PNE: "assegurar efetiva autonomia didática, científica, administrativa e de gestão financeira para as universidades públicas".

De acordo com o PNE é preciso "diversificar a oferta de ensino, incentivando a criação de cursos noturnos com propostas inovadoras, de cursos seqüenciais e de cursos modulares, com a certificação, permitindo maior flexibilidade na formação e ampliação da oferta de ensino". Essa oferta contribuiria de forma significativa para a expansão da educação superior pública, consolidando a universidade pública noturna, que atenderia, em geral, alunos trabalhadores oriundos de camadas menos favorecidas da sociedade. Vale lembrar que seriam menores os custos para essa expansão, uma vez que seria otimizada a capacidade instalada de cada universidade.

Entre os compromissos básicos do documento Uma Escola do Tamanho do Brasil encontra-se, a respeito da ampliação de vagas, o 
seguinte compromisso: "a expansão significativa da oferta de vagas no ensino superior, em especial no setor público e em cursos noturnos". Os elaboradores do programa preocuparam-se também com a desigualdade regional e com a interiorização do ensino superior e previram ações nesse sentido: "Estabelecer e implantar medidas que visem diminuir a desigualdade de oferta de cursos e vagas de graduação e pós-graduação em termos regionais e de interiorização".

Um dos objetivos presente no PNE era o de "estabelecer um amplo sistema interativo de educação a distância, utilizando-o, inclusive, para ampliar as possibilidades de atendimento nos cursos presenciais, regulares ou de educação continuada". Não se deve esquecer que essa modalidade de ensino, a distância, precisa ser implantada de forma progressiva para que a qualidade seja a mesma da presencial; o programa de governo contém proposta exatamente nesse sentido: "Implantar de forma progressiva uma rede universitária nacional de ensino superior a distância, com exigente padrão de qualidade".

No que tange à extensão, o PNE estabelece três metas de grande alcance social:

21. garantir, nas instituições de educação superior, a oferta de cursos de extensão, para atender as necessidades da educação continuada de adultos, com ou sem formação superior, na perspectiva de integrar o necessário esforço nacional de resgate da dívida social e educacional.

22. garantir a criação de conselhos com a participação da comunidade e de entidades da sociedade civil organizada, para acompanhamento e controle social das atividades universitárias, com o objetivo de assegurar o retorno à sociedade dos resultados das pesquisas, do ensino e da extensão.

23. implantar o programa de desenvolvimento da Extensão Universitária em todas as Instituições Federais de ensino Superior no quadriênio 2001-2004 e assegurar que, no mínimo, 10\% do total de créditos exigidos para a graduação no ensino superior no País será reservado para a atuação dos alunos em ações extensionistas. (BRASIL. PNE, 2001)

No programa do governo Lula assumiu-se também o compromisso de "Ampliar os programas de iniciação científica (PET e PIBIC) e criar programas de iniciação à docência e à extensão." 
O envolvimento das instituições de ensino superior com a formação e qualificação dos trabalhadores de empresas e, também, com a efetivação de programas de apoio e difusão tecnológica às micros, pequenas e médias empresas, está previsto em ações contidas no programa Uma Escola do Tamanho do Brasil: 1) "Envolver as universidades nos programas de ampliação de emprego e renda, e de formação e qualificação profissional dos trabalhadores" e 2) "Envolver as universidades nos programas de apoio e difusão tecnológica às micros, pequenas e médias empresas."

De uma ou de outra forma, cada uma dessas ações vincula-se ao tema financiamento e expansão dos recursos públicos que se dirigem às instituições de ensino superior brasileiras. Em primeiro lugar, é claro, àquelas que são diretamente vinculadas ao MEC, que são as Ifes.

\section{A proposta do Governo Lula (Primeira Versão): autonomia e FINANCIAMENTO}

As propostas apresentadas em dezembro de 2004 pelo Governo Lula para a educação superior - que pode ser considerada como uma primeira versão -, contidas no documento que "Estabelece normas gerais para a educação superior, regula o Sistema Federal da Educação Superior e dá outras providências", no que se refere à necessidade de financiamento, inicia-se por estabelecer como um dos objetivos a "expansão da rede pública de instituições de educação superior, pela criação de universidades, centros universitários e faculdades, e pelo aumento de ofertas de vagas, de modo a garantir a igualdade de oportunidades educacionais, com a meta de alcançar o percentual de $40 \%$ (quarenta por cento) das vagas do sistema de ensino superior até 2011" (artigo 3o, item VII). Há, portanto, que se alocar recursos financeiros que suportem o crescimento necessário para atingir 30\% das pessoas entre 18 e 24 anos estudando na educação superior - meta do PNE - e, além disso, $40 \%$ estudando na rede pública. Hoje, significaria passar de 1.137.119 estudantes para aproximadamente 2.800 .000 estudantes na rede pública

- uma expansão de $146 \%$.

O artigo 15, em seu parágrafo 2o, deixa claro que a "autonomia de gestão financeira e patrimonial consiste na capacidade de gerir recursos financeiros e patrimoniais, postos à sus disposição pela União ou recebidos 
em doação, bem como os gerados pela própria instituição", o que não nos deixa interpretar - como era comum fazermos em outros momentos - que o governo interpreta a autonomia de gestão financeira como a autonomia financeira, o que pode ser entendida como autonomia para que as instituições se lancem em busca dos recursos financeiros para a sua sobrevivência. Conforme analisa Sguissardi,

Nesse debate estão presentes duas concepções de autonomia atinentes à natureza pública ou privada das atuais Ifes e à questão de sua manutenção financeira. Na ótica oficial, embora se fale em autonomia de gestão financeira (termos constitucionais), o que de fato se defende é um conceito de autonomia financeira, presente tanto na LDB (apesar do teor do seu Artigo 54) quanto da PEC 370-a/ 96, que não prevê o pleno financiamento das Ifes e que supõe a busca por essas instituições de recursos suplementares junto a fontes privadas para suprir suas necessidades. (SGUISSARDI, 2000, p. 37)

Ao tratar especificamente do financiamento das instituições federais de educação - as instituições federais de ensino superior (Ifes) atuais estariam aí incluídas, os artigos 41 a 46 deixam claro que as universidades federais passariam a contar com uma autonomia maior do que têm hoje, mas continuariam imersas, ainda, em uma autonomia relativa no que se refere à gestão financeira.

A maior autonomia em relação à existente hoje refere-se aos seguintes aspectos:

1) os excedentes financeiros de um exercício "serão automaticamente incorporados ao exercício seguinte" (art. 42, § 3o);

2) os recursos "deverão ser repassados pela União sob a forma de dotações globais" (art. 44, § 1ํo);

3) as instituições elaborarão e executarão seus orçamentos, "assegurada a possibilidade de remanejamento entre rubricas, programas ou categorias de despesa" (art. 45).

Outras garantias ainda existiriam para as instituições, com relação ao montante de recursos financeiros:

1) a União aplicaria, "anualmente, nas instituições federais de educação superior, nunca menos de setenta e cinco por cento da receita constitucionalmente vinculada à manutenção e 
desenvolvimento do ensino" (art. 41), após deduzir da base de cálculo "a complementação da União aos Fundos de Manutenção e Desenvolvimento da Educação Básica e de Valorização dos Profissionais da Educação" (art. 41, Parágrafo Único), o chamado Fundeb;

2) cada instituição teria garantido que no ano seguinte os valores financeiros não poderiam ser inferiores "ao montante recebido, a mesmo título, no exercício financeiro imediatamente anterior" (art. 42);

3) o montante de recursos a ser recebido em um ano seria acrescido de recursos para cobrir despesas com o aumento de pessoal (vantagens ou aumento de remuneração, criação de cargos, empregos e funções, alteração de estruturas de carreira e admissão e contratação de pessoal) e as despesas de custeio seriam reajustadas pela "variação média dos preços dos insumos essenciais às atividades de ensino e pesquisa, conforme regulamento" (art. 42, § 1으, item II);

4) seriam excluídos dos cálculos os recursos relativos a fomento ao ensino e à pesquisa, aqueles vinculados a convênios, contratos e programas e os obtidos através de arrecadação própria (art. 42, § 2o, itens I, II e III).

Outras normas propostas nos permitem, entretanto, caracterizar, como fizemos neste estudo, a autonomia como uma autonomia relativa.

Em primeiro lugar, a dedução dos recursos do futuro Fundeb, da base de cálculo, poderá inviabilizar o aumento de recursos para as instituições federais, além de jogar o ensino superior e o ensino básico no mesmo campo de disputa por recursos financeiros, o que poderá acirrar ainda mais o embate entre os diferentes níveis de ensino. Nunca é demais lembrar as palavras de Julius Nyerere, relatadas por Marco Antonio Rodrigues Dias, então Diretor da Divisão de Ensino Superior da Unesco, durante seminário internacional promovido pela Associação Nacional dos Dirigentes das Instituições Federais de Ensino Superior (Andifes), realizado no Congresso Nacional, em 5 de setembro de 1995:

Em primeiro lugar, verificamos que, nos últimos dez anos, ampliou-se junto aos países em desenvolvimento um movimento visando a convencê-los não investir em educação superior. 
Buscou-se criar uma divisão entre os sistemas de educação, como se os recursos aplicados em ensino superior fossem extraídos do ensino de base. Na prática, procurou-se consolidar a idéia de que investir neste nível de ensino não se justifica porque apenas a "elite" seria beneficiada.

Tudo isto é - sejamos gentis - fruto de equívocos de apreciação.

O sistema educativo forma um conjunto. Se a educação de base não funciona bem, as repercussões serão negativas sobre a educação secundária. Se esta não se apresenta bem, o impacto nos estabelecimentos de ensino superior será negativo pois os estudantes que a ela ascender não estarão bem preparados e as instituições de ensino superior perderão tempo, energia e dinheiro para colocá-los em condições de acompanhar os cursos. Por sua vez, se as instituições de ensino superior estão mal organizadas, todo o sistema se desmoronará, pois os professores não serão formados de maneira adequada, não se realizarão as pesquisas educacionais necessárias à tomada de decisões pelos parlamentares na preparação das leis e pelos administradores na gestão dos sistemas educacionais. Além disso, se não há pesquisas sérias, os países em desenvolvimento acabam adotando modelos educativos que não são compatíveis com suas realidades e necessidades culturais.

Há algum tempo, tive oportunidade de assistir a um depoimento emocionante de um dos chefes de Estado africano mais expressivos, o tanzaniano Julius Nyerere, hoje afastado do poder (desde 1985), mas que se tornou uma figura mitológica e uma das personalidades africanas mais respeitadas em seu continente como fora dele. Visitando o Conselho Executivo da UNESCO, Nyerere recordou que, após a Independência, seu país logrou grande sucesso, nos anos sessenta e setenta, com uma política voluntarista em favor da alfabetização e da educação de base. No entanto, acentuou ele, a Tanzânia cometeu um grande erro. Por seguir os conselhos de especialistas internacionais, deixou de dar atenção particular ao ensino superior e, hoje, verificase que não dispõe de quadros nem de pesquisadores necessários ao seu desenvolvimento. Por outro lado, muito do que foi feito em educação de base perdeu-se pois faltaram condições para assegurar a qualidade devido a deficiências na formação de professores e na preparação de pesquisadores em educação, que normalmente são formados pelas universidades. Dirigindo-se, em particular, a seus colegas africanos, Julius Nyerere acentuou: 'não cometam o mesmo erro que nós!’ (ANDIFEs, 1996, p. 24-25; grifos nossos) 
A afirmação sobre a possibilidade de se inviabilizar o aumento dos recursos das Ifes se deve à amplitude que o Fundeb tomará na educação brasileira, financiando mais de 47 milhões de alunos matriculados na educação infantil, no ensino fundamental e médio, no ensino de jovens e adultos e na educação especial das redes estaduais e municipais. $\mathrm{O}$ coordenador da educação básica do MEC afirma que "é de fundamental importância uma significativa participação financeira da União, em caráter complementar ao Fundo, pela necessidade natural de se aportar recursos adicionais que alavanquem a melhoria e a universalização do atendimento na Educação Básica e minimizem os efeitos da redução de receitas dos entes governamentais 'transferidores' de recursos do âmbito do Fundo" (Fernandes, 2004; grifos nossos).

Nota-se, portanto, que as instituições federais podem ficar presas à condição imposta pelo artigo 42: "A participação de cada instituição federal de educação superior nos recursos destinados pela União à manutenção e desenvolvimento do ensino não poderá ser inferior ao montante recebido, a mesmo título, no exercício financeiro imediatamente anterior", pelo esgotamento dos recursos subvinculados para a educação superior e para o Fundeb.

\section{A proposta do Governo Lula (Segunda Versão): autonomia e} FINANCIAMENTO

Após discussões das propostas presentes no documento de dezembro de 2004, o MEC divulgou em 30 de maio de 2005 uma segunda versão com o título: "Estabelece normas gerais para a educação superior, regula a educação superior no sistema federal de ensino e dá outras providências".

A análise dessas duas versões nos permite afirmar que, mais uma vez, as propostas governamentais restringem a autonomia universitária, relativizando-a.

Na primeira versão, o artigo 15 , em seu parágrafo $2^{\circ}$, deixa claro que "a autonomia de gestão financeira e patrimonial consiste na capacidade de gerir recursos financeiros e patrimoniais, postos à sua disposição pela União ou recebidos em doação, bem como os gerados pela própria instituição" (grifos nossos).

Pode-se afirmar que essa redação permite interpretar que o governo entende a autonomia de gestão financeira como sendo aquela 
em que não há a necessidade de as instituições se lançarem em busca dos recursos financeiros para a sua sobrevivência.

Entretanto, a segunda versão apresenta um retrocesso e uma indevida limitação à autonomia de gestão financeira prevista na Constituição de 1988. No artigo 21, item III, está estabelecido que a "autonomia de gestão financeira e patrimonial, que consiste na capacidade de gerir recursos financeiros e patrimoniais, próprios, recebidos em doação ou gerados por suas atividades finalísticas" (grifos nossos). Nota-se, portanto, que ficam fora desse preceito de autonomia os recursos da União, o que claramente limita a autonomia universitária, além de contrariar o texto constitucional que não apresentou nenhuma restrição quanto aos recursos financeiros colocados à disposição das instituições.

A segunda versão não prevê o nível de detalhamento presente na primeira e retira a vinculação dos recursos do Fundeb. Nesse aspecto, a segunda versão significa um aprimoramento em relação ao que estava previsto anteriormente no primeiro documento do MEC, por evitar a disputa entre municípios, Estados e instituições de ensino superior.

O artigo 52 da segunda versão afirma que "A União aplicará, anualmente, nas instituições federais de educação superior, nunca menos de setenta e cinco por cento da receita constitucionalmente vinculada à manutenção e desenvolvimento do ensino." Alem de não existir a vinculação ao Fundeb são excluídos, convenientemente, do cálculo os seguintes recursos:

I - os recursos alocados às instituições federais de educação superior pelas entidades públicas de fomento ao ensino e à pesquisa científica e tecnológica e por suas congêneres privadas;

II - os recursos alocados às instituições federais de educação superior, por força de convênios, contratos, programas e projetos de cooperação, por órgãos e entidades publicas federais não participantes do sistema federal de educação superior, por outros órgãos e entidades públicos, federais ou não, bem como organizações internacionais;

III - as receitas próprias das instituições federais de educação superior, geradas por suas atividades e serviços;

IV - as despesas que não se caracterizam como de manutenção e desenvolvimento do ensino; 
$\mathrm{V}$ - as despesas com inativos e pensionistas das instituições federais de educação superior, sem prejuízo de seus direitos específicos;

VI - as despesas referentes a ações e serviços de saúde promovidos pelos hospitais vinculados às instituições federais de ensino, que serão contabilizadas para efeito do cumprimento do disposto no art. 198, §2º da Constituição Federal e art. 77 do Ato das Disposições Constitucionais Transitórias, e

VII - as despesas com pagamentos de débitos judiciais que tenham origem em legislação do período anterior à promulgação desta Lei, ou resultem de atos posteriores que não tenham decorrido de decisão emanada das instituições federais.

As instituições ainda teriam assegurado que "os excedentes financeiros de cada exercício, a qualquer título, serão automaticamente incorporados ao exercício seguinte", o que é um ganho em relação à situação vigente.

Entretanto, mais uma vez, o espectro da autonomia relativa aparece novamente. $\mathrm{O}$ artigo 53 da segunda versão diz que "cada universidade federal deverá habilitar-se ao regime de orçamentação global, devendo a União repassar os recursos pactuados em duodécimos mensais" (grifo nosso). Vê-se, portanto, que a universidade terá que se habilitar ao orçamento global, o que indica que existirão condições para essa habilitação. Quais? O texto não as explicita. Além dessa condição, o artigo 54 afirma que a "diferença entre o aporte de recursos previstos no art. 52 e o somatório dos orçamentos das instituições federais de ensino será destinado à expansão, interiorização e qualificação da educação superior pública federal" (grifos nossos), o que, mais uma vez, procura dirigir a aplicação dos recursos, caracterizando novamente uma limitação à autonomia das universidades.

\section{AleRTAS E PREOCUPAÇÕES}

Deve-se chamar a atenção para alguns aspectos que podem ser analisados examinando-se as Tabelas 1, 2 e 3, que seguem. A Tabela 1 apresenta uma simulação do que seriam os $75 \%$ dos recursos previstos no art. 212 da Constituição Federal em relação aos recursos das instituições federais, considerando-se que os recursos retirados ${ }^{1} \operatorname{dos} 18 \%$ 
para a educação retornaram ao fundo e que os inativos e pensionistas estariam sendo pagos com outros recursos do Tesouro da União.

Tabela 1 - Simulação do fundo de recursos para a educação superior* Valores em R \$ milhões, a preços de janeiro de 2003 (IGP-DI/FGV)

\begin{tabular}{|r|r|r|r|}
\hline Ano & $\begin{array}{c}75 \% \text { dos recursos mínimos } \\
\text { para a educação, sem a } \\
\text { existência do FEF, que a } \\
\text { União destinaria ao Fundo (B) }\end{array}$ & Gasto com as IFES (A) & \multicolumn{2}{c|}{$\begin{array}{c}\% \\
\text { (A)/(B) }\end{array}$} \\
\hline 1990 & 9.660 & 8.578 & 88,8 \\
\hline 1991 & 7.240 & 6.032 & 83,3 \\
\hline 1992 & 4.369 & 4.904 & 112,3 \\
\hline 1993 & 8.067 & 5.755 & 71,3 \\
\hline 1994 & 10.930 & 6.418 & 58,7 \\
\hline 1995 & 9.349 & 7.792 & 83,3 \\
\hline 1996 & 9.078 & 7.086 & 78,1 \\
\hline 1997 & 9.443 & 6.672 & 70,7 \\
\hline 1998 & 10.587 & 6.360 & 60,1 \\
\hline 1999 & 10.848 & 7.057 & 65,1 \\
\hline 2000 & 9.704 & 6.730 & 69,3 \\
\hline 2001 & 10.141 & 6.114 & 60,3 \\
\hline 2002 & 9.654 & 6.217 & 64,4 \\
\hline
\end{tabular}

Fonte: Primeira coluna: Cálculos deste estudo. Segunda coluna: Execução Orçamentária da União -

www.camara.gov.br

* Considerando o retorno de recursos como os do FEF, excluindo-se os valores pagos a aposentados, pensionistas e precatórios e excluindo-se os recursos próprios.

As Tabelas 2 e 3 mostram o significado da existência das desvinculações de recursos, como foi no caso do Fundo de Estabilização Fiscal (FEF) em 1998 e em 1999:

Tabela 2 - Recursos da educação, se não existisse o FEF.

Valores em R\$ milhões, a preços de janeiro de 2003 (IGP-DI/FGV)

\begin{tabular}{|l|r|r|}
\hline \multicolumn{1}{|c|}{ Discriminação } & \multicolumn{1}{c|}{$\mathbf{1 9 9 8}$} & \multicolumn{1}{c|}{1999} \\
\hline Receita Arrecadada de Impostos ${ }^{(1)}$ & 126.094 & 125.199 \\
\hline Transferências a Estados, DF e Municípios & 51.889 & 49.826 \\
\hline Receita Líquida de Impostos (Base de Cálculo) & 74.204 & 75.373 \\
\hline Percentual Mínimo para a Educação - 18\% & 13.356 & 13.568 \\
\hline
\end{tabular}

Fonte: (MF, 1998, p.53): SIAFI - CCONT/Secretaria do Tesouro Nacional.

(1) A Receita Arrecadada de Impostos é a Receita Líquida, ou seja, a arrecadada menos os incentivos fiscais e as restituições. 
Tabela 3 - Recursos da educação, com a existência do FEF. Valores em R\$ milhões, a preços de janeiro de 2003 (IGP-DI/FGV)

\begin{tabular}{|l|r|r|}
\hline \multicolumn{1}{|c|}{ Discriminação } & \multicolumn{1}{c|}{$\mathbf{1 9 9 8}$} & \multicolumn{1}{c|}{$\mathbf{1 9 9 9}$} \\
\hline Receita Arrecadada de Impostos ${ }^{(1)}$ & 126.094 & 125.199 \\
\hline Transferências a Estados, DF e Municípios & 51.889 & 49.826 \\
\hline Transferências para o FEF & 30.322 & 31.473 \\
\hline Receita Líquida de Impostos (Base de Cálculo) & 44.156 & 43.900 \\
\hline Percentual Mínimo para a Educação - 18\% & 7.947 & 7.901 \\
\hline
\end{tabular}

Fonte: (MF, 1998, p.54): SIAFI - CCONT/Secretaria do Tesouro Nacional.

(1) A Receita Arrecadada de Impostos é a Receita Líquida, ou seja, a arrecadada menos os incentivos fiscais e as restituições.

Foram desvinculados pelo FEF algo em torno de $\mathrm{R} \$ 5,0$ bilhões, e a proposta governamental não se pronuncia sobre essa desvinculação.

Nesse contexto, as instituições federais continuariam, portanto, sem terem nenhuma idéia de que recursos elas teriam à disposição no próximo exercício - o valor total continuaria sendo informado pelo governo.

Em segundo lugar, as dotações poderiam ser globais para as universidades, entretanto, a transformação da situação totalmente aleatória de hoje dar-se-ia paulatinamente, sendo que essas instituições deveriam atender determinadas condições que não foram especificadas. $\mathrm{Na}$ primeira versão, a habilitação para gerenciar o orçamento de forma global implicaria em descredenciamento das fundações de apoio. Qual o motivo dessa obrigatoriedade? Uma punição? O estabelecimento da autonomia relativa prevista nas propostas não descarta a utilização das fundações. Nenhum dos pontos alegados hoje para a existência das fundações foram resolvidos nas propostas: agilidade na execução de convênios e contratos, processos de compra e pagamentos desvinculados da Lei de Licitações (Lei n. 8.666), complementação salarial para docentes e técnico-administrativos etc.

Em terceiro lugar, a demanda por recursos além daqueles já estabelecidos dependerá da elaboração de um Plano de Desenvolvimento Institucional (PDI). Os planos de desenvolvimento institucionais, quando elaborados com a participação e o envolvimento daqueles que o executarão, sem imposição - principalmente sob a coação do financiamento - de metas a serem alcançadas, constituem-se em um valioso instrumento da gestão universitária, por estabelecer princípios, diretrizes, 
metas a serem alcançadas e responsabilidades; o PDI, nessas condições, colabora para que os rumos estabelecidos para a instituição sejam "perseguidos" por todos que têm responsabilidade em sua execução. Seria um grande risco para o país que o seu maior sistema de ensino superior deixasse de ser público e passasse a ser governamental e trabalhasse para atender os interesses do partido político ou do grupo dirigente que assumisse o Poder Executivo, temporariamente. A respeito do assunto, Guy Neave e Frans A. Van Vught afirmam:

Os contratos [que estabelecem condições] são um dos instrumentos mais poderosos da força do governo para orientar a ética fundamental da educação superior, para fazer com que esta deixe de ser uma instituição a serviço da sociedade e se converta, na realidade, em um organismo para o empreendimento público. Conferidos pelo governo ou por organizações do setor privado, os contratos possuem valor para a administração central, pois aparentemente proporcionam um poderoso incentivo para que as instituições de ensino superior satisfaçam as exigências do mercado. (Neave; Vught, 1994, p. 385386; grifos nossos)

Devemos lembrar que a negociação de um PDI para a expansão das atividades institucionais envolve uma negociação, no qual há, claramente, um lado mais frágil no embate com o governo: as instituições.

Em quarto lugar, a segunda versão abre a possibilidade de o governo federal destinar recursos às instituições estaduais e municipais e não há em nenhuma das versões um disciplinamento sobre a abertura de novas instituições públicas. Pode existir uma grande explosão de abertura de novas instituições, autorizadas a funcionar pelos poderes executivo e legislativo, sem nenhum cuidado com a divisão do "bolo de recursos" vinculado às instituições federais de educação superior e algum recurso - que poderia dirigir-se à expansão de cursos, à abertura de vagas e à melhoria das instituições já existentes - poderia ser direcionado para a abertura de novas instituições, às vezes para atender descompromissados interesses político-partidários.

\section{CONSIDERAÇÕES FINAIS}

As discussões sobre o ensino superior no governo Lula, que se iniciou em 2002, deveriam estar facilitadas pela existência de intensas 
discussões ao longo das campanhas eleitorais de que ele participou e pela concretização do programa Uma Escola do Tamanho do Brasil na eleição em que ele se tornou, finalmente, vitorioso em 2001. Esperavase, portanto, que o governo Lula promovesse ações de governo, através do MEC, no sentido de implementar as propostas que estão ali previstas. Se assim realmente ocorresse, uma primeira medida a ser implementada seria a de promover a derrubada dos vetos ao PNE, promovidos pelo presidente Fernando Henrique Cardoso. Seria preciso ainda que se implante uma verdadeira autonomia de gestão financeira para as universidades federais que propiciasse condições para que as instituições planejassem suas ações e estabelecessem metas de expansão a serem cumpridas.

A mercantilização exacerbada que está se instalando no interior das instituições públicas é um ponto a ser seriamente debatido e analisado nas esferas de decisão governamental por trazer o perigo de essas instituições perderem as condições para desempenharem o seu mais importante papel, estabelecido na LDB e no PNE e reconhecido pelo programa Uma Escola do Tamanho do Brasil: realizar pesquisa, oferecer programas de pós-graduação e desenvolver ações que permitam uma expansão que procure absorver alunos carentes e aluno-trabalhador em cursos noturnos.

A redução dos recursos originários do fundo público estaria levando as instituições públicas a agir como integrantes do quase-mercado educacional. Elas estariam atuando, via fundações privadas de apoio institucional, sobretudo na mercantilização da prestação de serviços, como forma de complementar os recursos necessários à própria manutenção, além de minorar a penúria produzida e ampliada a cada ano pelo quase congelamento salarial.

Muitos dirigentes, professores e servidores técnico-administrativos têm sido forçados a adotar essa postura para tentar garantir a sobrevivência institucional. É claro que o seguimento das normas impostas pelo quase-mercado tende, a cada dia que passa, a ser encarado como natural por muitos, dentro e fora das instituições, como se não houvesse de fato alternativa possível. A eficácia das condições materiais como determinante da mudança da consciência, mesmo entre intelectuais altamente qualificados, já tem sido largamente demonstrada por estudos sociológicos ao longo da história, de Marx a Bourdieu. 
No caso específico das Ifes, os valores de outras despesas correntes e investimentos originários do Tesouro Nacional demonstraram grande instabilidade e insuficiência durante tantos anos, o que nos leva a algumas perguntas intrigantes: como as instituições conseguiram expandir suas atividades nesse período? Como obtiveram recursos para a aquisição de equipamentos de laboratórios e atualização de seu parque de informática? Afinal, como sobreviveram?

Não existe uma resposta precisa para tais questões; podemos apenas fazer alusões a algumas possíveis explicações. Em alguns momentos, aliados políticos dos governantes angariavam recursos para as Ifes de suas regiões; em outros, a própria instituição conseguia convênios e contratos intermediados por fundações de direito privado que apóiam as instituições, e cujas execuções orçamentárias não fluem mediante a execução orçamentária institucional. Esse movimento iniciouse mais fortemente no ambiente de competição instalado em 1990, no governo Collor. Entretanto, no governo FHC, tal atitude foi incentivada e ganhou dimensões maiores, sobretudo pelo estancamento, a partir de 1995, do subterfúgio de se aplicar recursos excedentes de pessoal para gerar recursos próprios a partir de ganhos inflacionários, obtidos no mercado financeiro. Esse foi um mecanismo que propiciou, em muitos aspectos institucionais, a continuidade das atividades de ensino e de pesquisa (AMARAL, 2003, p. 199).

Podemos inferir desses fatos que no governo FHC não sobrou outra saída às Ifes se não investir em ações do quase-mercado, em busca de recursos para a sua sobrevivência. Passaram a atuar, através de convênios e contratos com fundações de apoio, abrindo cursos de especialização e de extensão que cobram taxas dos alunos; oferecendo assessorias, consultorias e prestando os mais diversos serviços laboratoriais etc. Estariam as instituições imersas no dilema "Universidade ou empresa de consultoria e serviços?" (SGUISSARDI, 2000), com todas as conseqüências negativas desse fato?

Diante da subsunção do educacional pelo econômico, pelo mercado, é hora de reafirmar-se que já não se trata de política educacional, mas de política genuinamente econômica, onde o econômico se sobrepõe ao político e ao social, e a universidade vê-se violentada em sua natureza mais específica e essencial, perdendo e correndo risco iminente, como indícios claros já o indicam, de transformar-se numa 
"fábrica de profissões exitosas ou em uma nova empresa de consultorias e serviços", conforme alertava o reitor J. Lavados M., da Universidade do Chile. (SGuissard, 2002)

Corre-se, dessa forma, o risco da privatização das instituições públicas por parte daqueles que nelas trabalham. São professores e técnicos que utilizam a infra-estrutura física e a credibilidade das instituições para executarem convênios e contratos que, muitas vezes, impedem esses profissionais de desempenhar, com eficácia, as suas funções institucionais.

Como uma multiversidade, as Ifes podem, também, estar invertendo meio e fim. A melhor exemplificação desse efeito é a prestação de serviços realizada pelas instituições. "É preciso distinguir aqueles serviços que servem à geração de conhecimentos daqueles que, embora solicitados pela sociedade, nada têm a ver com os objetivos da Universidade" (CERqueIRA LeITE, 1989, p. 82).

Os docentes, pressionados a dar mais aulas e a aumentar quantitativamente a produção intelectual dessas instituições, e forçados a se envolver com as práticas do quase-mercado educacional, atrás de complementação salarial e de recursos financeiros competitivos para manter sua condição de trabalho, viram-se imersos em um ambiente de disputa e de defesa de interesses individuais.

Os valores "solidariedade, cooperação, colegialidade, tolerância, paz, justiça e outros de mesma linha são substituídas por outros valores economicistas, como eficiência, produtividade, competitividade, utilidade, funcionalidade" (DiAs Sobrinho, 2002, p.16). Estaria já se operando um deslocamento ético temido por Dias Sobrinho, pela lógica economicista presente nas orientações do novo liberalismo pós-crise do Estado de bem-estar social europeu?

Não podemos concordar que as mudanças implantadas nas instituições de ensino superior, muitas delas relacionadas ao financiamento, sejam as únicas e as possíveis, nesse momento político e econômico mundial. A sociedade humana é muito complexa para admitir homogeneidade, linearidade e a infalibilidade de um pensamento único. $\mathrm{O}$ comando, a direção dos projetos implantados talvez devessem fazer parte, nas palavras de Nogueira Batista, de um consenso brasileiro, baseado em uma relação de interdependência - e não de dependência do mundo - e um projeto de nação 
que deseja cooperar com outras nações e delas receber cooperação, sempre porém em base de igualdade e de respeito mútuo, sem qualquer renúncia a sua integridade territorial nem a sua soberania. Projeto que passa por uma política externa soberana que não seja, como muitas vezes no passado, um pacto entre as lideranças internas e externas, à custa do interesse mais global do país. (BATISTA, 1999, p. 59-60)

O processo de degenerescência a que as instituições públicas estão sujeitas poderia levá-las, no médio prazo, a se tornarem instituições puramente utilitaristas, com alguns poucos núcleos de excelência científica e intelectual que, para sobreviverem nesse patamar, teriam que angariar recursos no mercado, vinculando os seus trabalhos e projetos aos interesses dos financiadores, sejam estes governos ou empresas. Como consequiência, o Brasil perderia um complexo de instituições que além de "estimular a criação cultural e o desenvolvimento do espírito científico e do pensamento reflexivo", como prevê a LDB, deveria ter condições para "encontrar solução para os problemas atuais, em todos os campos da vida e da atividade humana e abrindo um horizonte para um futuro melhor para a sociedade brasileira, reduzindo as desigualdades", como estabelece o PNE.

\section{ABSTRACT}

This study discusses the course of the third level educational reform initiated by Lula's government, from the viewpoint of autonomy and finances, as well as presenting the proposals for higher education contained in the political manifesto Uma Escola do Tamanho do Brasil ('A school the size of Brazil'), launched during the 2001 electoral campaign. Warnings and preoccupations are expressed with regard to several points presented in the two already published versions. I concluded that a historical process seems to exist whereby real autonomy will not be established in Brazilian federal universities, given that the regulations tend to relativize it, leaving the conditions for financial support vague and obscure.

Key words: autonomy, financial support, third level education

\section{NOTAS}

1. Recursos retirados pelas desvinculações impostas, primeiro pelo Fundo Social de Emergência (FSE), depois pelo Fundo de Estabilização Fiscal (FEF) e, depois, pela Desvinculação das Receitas da União (DRU), que se encontra em vigor. 


\section{REFERÊNCIAS}

AMARAL, N. C. Financiamento da educação superior: estado x mercado. São Paulo: Cortez e Piracicaba-SP, Unimep, 2003.

ANDIFES. Mudança e desenvolvimento da universidade pública na América Latina. Brasília, Anais do Seminário Internacional da Andifes, 5 set. 1995, 1996.

BATISTA, P. N. O consenso de Washington: a visão neoliberal dos problemas latino-americanos. In: LIMA SOBRINHO, B. et al. Em defesa do interesse nacional: desinformação e alienação do patrimônio público. São Paulo: Paz e Terra, 1999.

BRASIL. PNE. Plano Nacional de Educação. Lei n. 10.172/2001. Brasília, Congresso Nacional, 2001.

BRASIL. INEP. Sistema Nacional de Avaliação da Educação Superior. Ministério da Educação, 2003.

CERQUEIRA LEITE, R. Autonomia da universidade e governo das instituições de ensino superior. Educação Brasileira, Brasília, 11 (22): 81-86, 1ํㅗ.

DIAS SOBRINHO, J. Universidade e avaliação: entre a ética e o mercado. Florianópolis: Insular, 2002.

FÁVERO, M. L. A. Universidade do Brasil: das origens à construção. Rio de Janeiro: Editora da UFRJ, 2000a.

Universidade do Brasil: guia dos dispositivos legais. Rio de Janeiro: Editora da UFRJ, 2000b.

FERNANDES, F. C. Fundo de manutenção e desenvolvimento da educação básica e de valorização dos profissionais da educação - Fundeb: o que é e o que pretende. Brasília, 2004. Disponível em: <www.mec.gov.br> Acesso em: 10 jun. 2005.

NEAVE, G.; VAN VUGHT, F. A. Prometeo encadenado: Estado y educación superior en Europa. Barcelona: Gedisa, 1994.

SGUISSARDI, V. O Banco Mundial e a educação superior: revisando teses e posições? Universidade e Sociedade. Brasília, Ano X (22): 66-76, nov. 2000.

Rumo à universidade competitiva: na modernização conservadora a universidade perde sua face, sua alma e sua identidade históricas. In: Perspectiva, Florianópolis, 20 (2): 229-237, jul.-dez./2002. 
